\title{
OS MAÇONS E A MODERNIZAÇÃO EDUCATIVA NO BRASIL NO PERÍODO DE IMPLANTAÇÃO E CONSOLIDAÇÃO DA REPÚBLICA
}

DOI: http://dx.doi.org/10.1590/2236-3459/71642

\author{
Giana Lange do Amaral \\ Universidade Federal de Pelotas (Ufpel), Brasil
}

$\cos 80$

\begin{abstract}
Resumo
A atuação de maçons no processo de modernização da educação brasileira, remonta ao século XIX, respaldada por idéias liberais e iluministas. Se consolida nas primeiras décadas do regime republicano, influenciada pelo ideário positivista e anti-jesuítico, em defesa do ensino elementar público, laico e obrigatório. No Brasil, a Maçonaria adaptou-se às condições específicas e necessidades regionais de onde se instalou. Portanto ela não deve ser compreendida num sentido unívoco, sendo mais fácil identificar a ação e engajamento ideológico de maçons e não da Maçonaria propriamente dita. O presente estudo, fundamentado pela História Cultural, privilegia o uso de periódicos maçônicos e busca destacar práticas políticas dos maçons como intelectuais, gestores, legisladores, escritores, jornalistas e professores, bem como as Lojas Maçônicas como potenciais espaços de sociabilidades e organização ideológica.

Palavras-chave: maçons e a educação, periódicos maçônicos, maçonaria brasileira, história intelectual, modernização educativa.

\section{THE MASONS AND THE EDUCATIONAL MODERNIZATION IN BRAZIL DURING THE PERIOD OF IMPLEMENTATION AND CONSOLIDATION OF THE REPUBLIC}

\begin{abstract}
The role of Freemasons in the process of modernization of the Brazilian education, dating back to the 19th century, supported by liberal ideas and enlightenment. Consolidates in the early decades of the Republican regime, influenced by positivist ideals and Jesuit oposiantion, in defense of public education, secular and mandatory. In Brazil, Freemasonry has adapted to the specific conditions and needs of regional where he settled. So it should not be understood in a univocal sense, being easier to identify the action and ideological engagement of Masons and not of Freemasonry. The present study, substantiated by the Cultural History, favours the use of Masonic periodicals and search highlight political practices of the Freemasons as intellectuals, managers, legislators, writers, journalists and teachers, as well as the Masonic Lodges as potential areas of social arrangements and ideological organization.

Keywords: freemasons and education, masonic periodicals, Brazilian Freemasonry, intellectual history, educational modernization.
\end{abstract}

\section{LOS MASONES Y LA MODERNIZACIÓN EDUCATIVA EN BRASIL DURANTE EL PERÍODO DE IMPLEMENTACIÓN Y CONSOLIDACIÓN DE LA REPÚBLICA}

\section{Resumen}

El papel de los masones en el proceso de modernización de la educación brasileña, que se remonta al siglo 
19, apoyado por ideas liberales y la iluminación. Consolidado en las primeras décadas del régimen republicano, influenciado por los ideales positivistas y anti jesuitas, en defensa de la educación pública, laica y obligatoria. En Brasil, masonería ha adaptado a las condiciones específicas y necesidades de la regional donde se estableció. Por lo que no debe entenderse en el sentido predicado unívoco, siendo fáciles de identificar la acción y el compromiso ideológico de los masones y no de la masonería. El presente estudio, fundamentado por la historia Cultural, la suerte favorece el uso de periódicos masónicos y a buscar destacar prácticas políticas de los masones los intelectuales, administradores, legisladores, escritores, periodistas y profesores, así como masónico alberga las áreas potenciales de acuerdos sociales y organización ideológica. Palabras clave: masones y educación, revistas masónicas, masonería brasileña, historia intelectual, modernización de la educación.

\section{LES FRANCS-MAÇONS ET LA MODERNISATION DE L'ÉDUCATION AU BRÉSIL AU COURS DE LA PÉRIODE DE MISE EN CEUVRE ET LA CONSOLIDATION DE LA RÉPUBLIQUE}

\section{Résumé}

La performance des francs-maçons dans le processus de modernisation de l'enseignement brésilien, datant du XIXe siècle, soutenue par les idées libérales et éclairés. Si consolide dans les premières décennies du régime républicain, influencé les idées positiviste et anti-jésuitique dans la défense de l'éducation élémentaire publique, laïque et obligatoire. Au Brésil, la franc-maçonnerie adapté aux conditions spécifiques et aux besoins régionaux où installés. Donc elle ne devrait pas être comprise dans un sens univoque, étant plus facile à identifier l'action et l'engagement idéologique de francs-maçons et non de la franc-maçonnerie elle-même. Cette étude, sur la base na l'histoire culturelle, favorise l'utilisation des revues maçonniques et vise à mettre l'accent sur les pratiques politiques des francs-maçons comme des intellectuels, des gestionnaires, des législateurs, des écrivains, des journalistes et des enseignants, aussi bien que lesloges maçonniques comme des espaces potentiels de sociabilité et de l'organisation idéologique.

Mots-clés: francs-maçons et l'éducation, périodiques maçonniques, franc-maçonnerie brésilienne, histoire intellectuale, modernisation de l'éducation. 


\section{Considerações iniciais}

A atuação de maçons e da maçonaria no contexto educacional brasileiro ainda é uma temática pouco estudada no âmbito da História da Educação. Neste texto, destaco encaminhamentos preliminares sobre o estudo de sua influência no processo de modernização educacional, que se consolida entre as últimas décadas do século XIX e primeiras do século XX. É sobre esse período, no qual ocorre a implantação e consolidação do regime republicano no Brasil, que desenvolvo reflexões e análises. ${ }^{1}$

No presente estudo, tendo como fundamento teórico-metodológico a História Cultural, uso como fontes jornais, boletins, discursos e bibliografia referentes à temática. Algumas dessas fontes possibilitam leituras de manifestações contemporâneas aos acontecimentos que envolviam a tão propalada modernidade advinda do sistema republicano. Assim, é possível uma aproximação dos discursos emitidos na época em relação a projetos de sociedade e suas instituições sociais. Muitos são os discursos apaixonados, realizados sob o influxo de interesses e compromissos político-ideológicos. No entanto, o caráter polêmico e, por vezes, passageiro das publicações, representam um produto cultural de sujeitos específicos em um determinado contexto histórico. ${ }^{2}$ Nesse sentido, Chartier (1990) enfatiza que os historiadores da cultura devem criar suas próprias estratégias na leitura dos textos com os quais trabalham, pois eles afetam o leitor de forma individual e variada. Deve-se ter claro que os documentos e os referenciais bibliográficos que descrevem ações do passado possuem uma intencionalidade e um engajamento nas relações de poder que se estabelecem. E no caso da ação de intelectuais maçons, no espaço educacional brasileiro, é particularmente intrigante constatar nos trabalhos acadêmicos a pouca visibilidade e identificação de suas práticas políticas como oriundas de um espaço que os identifica: a maçonaria.

O objetivo, com esta análise, é estabelecer interfaces no âmbito políticoeducacional e cultural da presença de maçons no processo de implantação da República no Brasil. Isso a partir da atuação de intelectuais maçons e dos espaços culturais e educacionais por eles ocupados. A Maçonaria é aqui considerada um locus potencial e agregador, como um espaço de sociabilidade, de intelectuais que fundamentam ideias que se consolidam no processo de implantação da República. Os maçons, que no seu espaço coletivo, as lojas maçônicas ${ }^{3}$, compartilhavam aspectos do ideário liberal e positivista, buscaram uma nova sociedade baseada na ordem e no progresso. Serão eles que, nas suas individualidades, com sua atuação político-cultural como indivíduos, mas que pertencem a um grupo (ou grupos) que os orienta e sinaliza caminhos, pensaram e organizaram a possibilidade de implantação de um novo regime. Um regime que se opunha ao escravismo, às práticas monárquicas e às influências clericais e jesuíticas, consideradas retrógradas e ultrapassadas, defendendo o laicismo no campo educacional.

Como afirmado em Amaral (2005), no Brasil, todo o processo de Proclamação da República resultou também do trabalho de políticos ligados à Maçonaria. Isto se torna

\footnotetext{
${ }^{1}$ Este trabalho resulta de estudos apresentados em Amaral (2005) e encaminhados quando da realização do estágio pós doutoral no Instituto de Educação da Universidade de Lisboa (2014-2015), sob orientação de Justino Magalhães. A grafia dos textos aqui apresentados é mantida conforme os originais.

${ }^{2}$ Como afirma Luca (2015), no Brasil, o uso de periódicos generalizou-se, desde meados de 1980, a ponto de ser um dos traços distintivos da produção acadêmica brasileira.

${ }^{3}$ Loja é o lugar ou a reunião em que se congregam os maçons para o trabalho seu específico.
} 
evidente quando se constata que: o Manifesto Republicano de 1870 foi redigido pelo GrãoMestre Saldanha Marinho, recebendo assinaturas de grande número de maçons; o "Clube Republicano" era presidido pelo maçom Quintino Bocaiúva; eram maçons os componentes do primeiro Governo Provisório ${ }^{4}$. 0 emergente sistema republicano estava bastante ligado aos interesses da Maçonaria, que tratou de usar de sua influência junto à sociedade brasileira, para solidificar as determinações políticas da Constituição Republicana, especialmente no que se relacionasse à separação da lgreja e do Estado. Este foi mais um fato que contribuiu para que o conflito entre a Igreja e a Maçonaria se tornasse tão acentuado.

Realizar um estudo que envolva a Maçonaria requer que, necessariamente, estabeleçamos sua relação com o Catolicismo. A Igreja e a Maçonaria exerceram influência decisiva em muitos acontecimentos políticos e sociais de nosso país. Entraram no século XX num clima de conflito político-ideológico, movido por questões internas que diziam respeito à nossa política nacional (como o processo da implantação do sistema republicano), assim como por questões oriundas das determinações do Vaticano que acentuaram o processo de romanização da lgreja e de perseguição desta aos maçons.

Nesse quadro, há que se destacar, como será analisado a seguir, a dispersão organizativa da maçonaria brasileira que apresentou muitas cisões e disputas políticas pautadas por diferentes vínculos regionais, nacionais e internacionais. Tal fato dificulta a compreensão de seus aspectos organizacionais e de sua atuação como grupos que em alguns momentos rivalizavam entre si.

\section{A maçonaria como espaço de sociabilidade}

A influência da maçonaria na história do Brasil e na educação brasileira é evidente. No entanto, conforme já afirmado, em função de as temáticas ligadas à maçonaria serem assuntos ainda pouco tratados pela historiografia brasileira, percebe-se, posições divergentes e talvez não suficientemente exploradas, entre os maçonólogos e historiadores, o que torna difícil traçar, de forma concisa, o perfil desta instituição.

Em um artigo publicado em 1997, Célia Azevedo identifica a perda de visibilidade da maçonaria na história do Brasil. Para tanto, destaca modos de abordagem sobre o tema maçonaria por parte de três historiadores que imprimiram tendências duradouras na historiografia do Brasil monárquico: Francisco Adolfo de Vernhagen (1818-1878), Manuel de Oliveira Lima (1867-1928) e Caio Prado Jr. (1907-1990). Segundo a autora, os dois primeiros autores convergem ao ressaltar o empenho dos maçons brasileiros na defesa da nação emergente e de um governo pautado prioritariamente pela Lei, sendo a identidade maçônica preenchida com dois atributos básicos: nacionalismo e constitucionalismo.

Azevedo (1997) ressalta que na abordagem de Prado Jr., aos maçons brasileiros interessava a solução das questões internas do país, o que os levava a agir mais como brasileiros do que como maçons. Utilizavam-se da maçonaria para atuarem de forma mais

\footnotetext{
${ }^{4}$ Os políticos maçons deste governo eram o Marechal Deodoro da Fonseca, primeiro presidente brasileiro, e seus ministros que ocupavam as seguintes pastas: Aristides Lobo, Interior; Campos Sales, Justiça; Rui Barbosa, Fazenda; Quintino Bocaiúva, Relações Exteriores; Demétrio Ribeiro, Agricultura, comércio e Obras Públicas; Benjamim Constant, Guerra; Eduardo Wandelkolk, Marinha (GOMES, 1975, p. 139). Como curiosidade cabe ressaltar que Deodoro da Fonseca foi iniciado na Loja Rocha Negra, de São Gabriel, Rio Grande do Sul.
} 
orientada e organizada. Havia mais uma troca de favores entre a maçonaria e os brasileiros do que uma simbiose entre eles:

A história da maçonaria não teria passado, portanto, na visão de Prado Jr, de uma relação instrumental, de importância momentânea e - por que não explicitar? secundária. Nossos maçons não foram em sua essência maçons, mas sim brasileiros, e ao final de contas a importância de sua ação política parece residir precisamente nesse fato. (AZEVEDO, 1997, p. 187).

Assim, como muitos historiadores ancoram seus referenciais em Prado Jr., a autora afirma que em vários estudos se constata uma perda da identidade maçônica em relação a vários personagens de destaque no cenário político brasileiro do século XIX, cuja trajetória é destacada sem que seja mencionada sua filiação maçônica. (AZEVEDO, 1997, p. 185$)^{5}$.

Ressalto que o mesmo ocorre em relação aos personagens de destaque no âmbito educacional brasileiro. Suas práticas e trajetórias como intelectuais carecem de informações sobre o fato de serem maçons e terem participado desse importante espaço de sociabilidade - a maçonaria - que definia estratégias de distribuição e apropriação de capital cultural. Suas atuações, como políticos, jornalistas, escritores, professores e gestores, aparecem nos estudos acadêmicos descoladas de seu pertencimento à maçonaria. Indubitavelmente essa é uma lacuna a ser preenchida a partir de estudos que retirem a maçonaria de sua invisibilidade no contexto político-educacional brasileiro. $E$ assim, que sejam formuladas novas questões às fontes de pesquisa, que levem em conta a compreensão das especificidades da instituição maçônica, as características sócioeconômicas e culturais dos maçons, sua influência sócio-cultural, os distintos posicionamentos dessa ordem em relação a questões regionais, nacionais e internacionais.

Se era lugar comum ser intelectual e maçom no período aqui estudado, os historiadores da educação devem contextualizar esse fato. Estabelecer relações com o significado de pertença a este grupo ${ }^{6}$. Conforme demonstra Barata (1999), o desejo de usufruir do auxílio mútuo praticado pela ordem, a percepção da maçonaria como um espaço de convívio e mobilidades sociais e o entendimento do espaço maçônico como escola de virtudes, de debate de ideias e de aprendizado do viver em coletividade, eram as principais razões que levavam os homens a ingressarem na maçonaria. Ser maçom, para certos setores da sociedade, significava uma forma de influir, de participar da estruturação do Estado Brasileiro.

Nesta linha de análise, reitero que a história da educação brasileira carece de estudos que abordem a atuação dos intelectuais brasileiros estabelecendo uma identificação de suas reflexões e práticas políticas de vanguarda com a maçonaria compreendida como um espaço de sociabilidade agregador de expectativas do

\footnotetext{
${ }^{5}$ Azevedo (1997, p. 186) também afirma que "é interessante observar aqui que outro importante historiador contemporâneo, Sérgio Buarque de Holanda, limitou-se a registrar em algumas linhas o declínio da maçonaria numa suposta substituição desta pelo movimento positivista. Não oferece, no entanto, explicações e evidências para esta tese apenas acenada no início de um capítulo significativamente intitulado "Da Maçonaria ao Positivismo". Haveria aqui implicitamente uma vontade de encerrar definitivamente o assunto maçonaria na história do Brasil? Ver: O Brasil Monárquico - Do Império à República, tomo 2, vol. 5, São Paulo, Difel, 1985, pp. 289-305."

${ }^{6}$ Esse pode ser o caso de maçons que se destacaram no âmbito político-educacional brasileiro como o Padre Diogo Antônio Feijó, Rui Barbosa, Francisco Rangel Pestana, dentre outros.
} 
pensamento da modernidade.

Azevedo (1997), Barata (1999) e Morel (2001) destacam a potencialidade do conceito de sociabilidade para as análises históricas que envolvem a maçonaria e seu contexto de atuação. Sobre o retorno e utilização desse conceito, Morel (2001) ressalta que

uma obra póstuma de Augustin Cochin (1925) valorizou o papel das associações para compreender a eclosão da Revolução Francesa. Tal trabalho não teve repercussão imediata, mas seria recuperado por François Furet (1978). As sociabilidades - como tema e instrumental teórico e metodológico - fariam entrada definitiva no campo da pesquisa histórica acadêmica com a obra de Maurice Agulhon (1968 e 1977), um dos reconhecidos herdeiros da Ecole des Annales, inicialmente com sua tese e, na década seguinte, com um balanço crítico das possibilidades e perspectivas de tal abordagem. (MOREL, 2001, p. 4).

Maurice Agulhon publicou em 1966 a obra La sociabilité méridionale, reeditada dois anos depois com o título de Pénitents et franc-maçons de l'ancienne Provence. Esse estudo que destaca a fase final do antigo Regime sob o prisma das associações, têm no conceito de sociabilidade um caminho para compreender as realidades sociais a partir da constituição de grupos sociais organizados. Segundo Agulhon (1987, p. 37), "essa sociabilidade da qual a vida associativa é a forma principal vem do Antigo Regime, pelo menos, e comporta constância e unidade através da diversidade dos tipos de associação sucessivos".

Esse autor, no texto Visão dos Bastidores apresentado no livro Ensaios de EgoHistória, em tom confessional como é a proposta da referida obra, ressalta sua contribuição na inserção da palavra sociabilidade no vocabulário dos historiadores e reclama a falta de reconhecimento por dois de seus pares:

[...] eu pusera bem (ou contribuíra em grande parte para isso) no mercado do vocabulário histórico a palavra sociabilidade que lá figura desde então [desde a publicação de sua obra La Sociabilité Méridionale]. A partir de 1967, André Bourde utilizava-a na sua contribuição para a Histoire du Diocese de Marseille, e Emmanuel Le Roy Ladurie nos seus capítulos da Histoire Du Languedoc de Privat. Os dois conheciam a minha obra e inspiraram-se evidentemente nela nesse aspecto. Ousarei confessar que o orgulho que senti por ser um inspirador foi largamente contrabalançado pelo despeito de eles não referirem o meu nome, nem em bibliografia nem em nota? Saibamos também ver as nossas fraquezas e confessemos que delas faz parte uma certa dose de vaidade de autor. (AGULHON, 1987, p. 40).

Morel (2001) afirma que Agulhon passa a propor o conhecimento das sociabilidades pela densidade da existência de associações constituídas e suas mutações num quadro geográfico e cronológico delimitado, ou seja,

uma história da vontade associativa com dados quantitativos e comparativos, com suas mudanças no tempo e no espaço. O referido autor chegava mesmo a tocar na questão das identidades culturais, discutindo a aptidão de determinados grupamentos humanos regionais para as formas estudadas, no caso, a passagem das confrarias para as maçonarias na Provence. (MOREL, 2001, p. 4).

No artigo Maurice Agulhon e a categoria Sociabilidade, Canal (2015, p. 3) ressalta que para esse autor a sociabilidade quer dizer a qualidade de ser sociável, ou seja, "é o equivalente dos sistemas de relações que confrontam os indivíduos uns com os outros ou 
que os reúnem em grupos mais ou menos naturais, mais ou menos forçados, mais ou menos estáveis, mais ou menos numerosos". Canal afirma que, na produção historiográfica de Agulhon, a categoria sociabilidade evoluiu

desde uma tripla especificação inicial - âmbito regional no plano geográfico, séculos XVIII e XIX no cronológico, e, no temático, vida associativa - para uma aceção mais ampla e aberta que chegava a assimilar a história da sociabilidade à da vida quotidiana. (CANAL, 2015, p. 3).

Segundo esse autor,

a sociabilidade informal complementa a vida associativa. Entre os temas abordados encontram-se os cafés, as tabernas, a vida familiar e as praças, as associações operárias e militares, o termalismo e a vida de salão, os agrupamentos políticos e as lojas maçónicas, os orfeãos e o desporto. O resultado é um imenso campo de estudo e, por conseguinte, a génese de um grande número de trabalhos tendo como denominador comum a sociabilidade. Disciplinas científicas em muitas ocasiões desconectadas e mesmo ignorando-se mutuamente, como a psicologia social, a sociologia, a história e a antropologia, convergiram parcialmente graças a esta categoria. (CANAL, 2015, p. 4).

Para Azevedo (1997), a noção de sociabilidade, introduzida por Agulhon no vocabulário dos historiadores dos Annales, adquiriu crescente relevo na história social e cultural, sendo fundamental para a compreensão da história da maçonaria. No entanto, a autora ressalta que esse autor não teve muitos seguidores na França, no tocante à história da maçonaria propriamente dita. O mesmo pode-se afirmar em relação ao Brasil, especialmente nos (ainda) poucos estudos históricos sobre a maçonaria e a educação no âmbito da História da Educação que podem desbravar as potencialidades da leitura de Maurice Agulhon.

\section{Os maçons no contexto da modernidade educacional}

Para identificar e caracterizar o quadro de modernização educacional e a atuação dos maçons e da maçonaria torna-se fundamental reconhecê-lo no contexto da Modernidade. Modernidade compreendida aqui como uma designação abrangente de um largo século XIX, período de 1789 a 1914, e de um curto século XX, de 1914 a 1945 (HABERMAS, 2000), em que mudanças intelectuais, sociais, políticas e econômicas refletemse na crescente racionalização em todos os aspectos da vida social e do pensamento humano. Os eventos ligados à Revolução Francesa, à constituição do lluminismo e do industrialismo (capitalismo), representam a superação do pensamento e das tradicionais organizações do medievo. O rompimento com o pensamento escolástico, método de pensamento crítico intrínseco aos preceitos da Igreja Católica, o uso da razão como forma autônoma de construção de conhecimento, desvinculado de preceitos teológicos, base do lluminismo, foram fundamentais na construção do pensamento moderno no largo século XIX.

O empirismo iluminista que estabelece a razão e a ciência como a verdadeira forma de se conhecer o mundo e fortalece os ideais de laços sociais igualitários, abalou a estruturas do absolutismo real, cujos pilares sociais e políticos assentavam-se em bases teológicas. As ideias iluministas serão, também, o sustentáculo ideológico dos movimentos de independência das colônias americanas, bem como da implantação dos regimes republicanos na Europa e nas Américas. 
No contexto da Modernidade, a maçonaria, uma instituição filosófica e filantrópica de natureza discreta, privada e de caráter secreto, foi uma das mais expressivas formas de organização política oposicionista ao absolutismo real e ao poder clerical, especialmente do jesuitismo, representando um lugar de circulação de ideias e práticas modernas, destacadamente no largo século XIX. A atuação política de maçons e da maçonaria foi fundamental na constituição, divulgação e implantação do ideário da llustração, do Positivismo e Liberalismo.

Como afirma Morel (2008),

\begin{abstract}
guardada pelo segredo, a maçonaria constitui-se em 'poder indireto', uma vez que se torna um local de discussão de questões de cunho político, sem contudo, estar sob o controle e a vigência do Estado. O segredo permitia a esta instituição apresentar-se como apolítica, mesmo configurando-se como um importante agente político.

Contudo a tentativa de escapar do controle do Estado não é a única explicação para uma postura revolucionária ou oposicionista da maçonaria. Ao contrário, o posicionamento dessa instituição frente aos regimes políticos variou de acordo com uma série de fatores (elementos históricos, religião, região, conjunturas) que ultrapassam o fato de constituir-se como um lugar protegido pelo segredo. Até por seu ideário de progresso, ainda que difuso, as maçonarias tendem a ser mais evolucionistas e pregar mudanças graduais.
\end{abstract}

(MOREL, 2008, p. 44-45).

Esse autor utiliza muito a expressão "as maçonarias" e não "a maçonaria", levando em conta que não existiu apenas uma maçonaria como centro aglutinador e atemporal, mas sim, diversas organizações maçônicas ao longo do tempo. Ele ressalta a importância de que se compreenda a maçonaria não de maneira isolada da sociedade, mas como uma associação presente em diferentes situações históricas, atravessada por questões de cada momento e possuindo características próprias oriundas de divisões e contradições assim como de conquistas e inovações. (MOREL, 2008, p.10).

A Maçonaria, no século XVIII, espalhou-se rapidamente pela Europa e América, tornando-se

o lugar de encontro de homens de certa cultura com inquietações intelectuais, interessados pelo humanismo como fraternidade, acima das separações e oposições sectárias, que tantos sofrimentos haviam causado, a Reforma de uma parte e a Contra-Reforma de outra [...] uma reunião de homens que acreditam em Deus, que respeitam a moral natural e querem conhecer-se e trabalhar juntos apesar da diversidade de suas opiniões religiosas e de sua filiação a confissões ou partidos mais ou menos opostos. (BENIMELI et al., 1983, p. 56-57).

Pode-se afirmar, entretanto, que a Maçonaria é uma instituição que, baseada em símbolos e rituais secretos, não é uma seita religiosa na acepção comum do termo.

Com o tempo, embora tendo presente seus princípios fundamentais e seu esquema original, essa instituição passou a apresentar diversas ramificações. As diferenças na interpretação e na prática ritual do que se pode considerar o núcleo maçônico básico - as Constituições de Anderson - e o trabalho simbólico dos ritos iniciáticos aos três primeiros graus - aprendiz, companheiro e mestre -, se refletiram na divisão da Maçonaria em numerosas denominações e ritos, muitas vezes antagônicos entre si. Essas divisões nos afastam, portanto, da compreensão da Maçonaria num sentido unívoco. O fato de não haver um órgão controlador internacional que seja reconhecido por todas as potências 
maçônicas ${ }^{7}$, acarreta uma falta de clareza quanto aos princípios básicos que fundamentariam o que poderia se considerar como Maçonaria "autêntica ou regular". (AMARAL, 2005).

Pelo que foi até aqui exposto, constata-se que estabelecer uma definição satisfatória e completa do que vem a ser hoje a Maçonaria não é tarefa fácil. Essa instituição adaptou-se, inclusive, à mentalidade de cada época e país que a praticou, pois ora assumiu um caráter de difusão da crença na existência de Deus, ora representou um movimento filosófico que busca a Verdade, livre de orientação e de opinião.

No Brasil, por vezes, as contradições entre o discurso e a prática maçônica resultaram da manipulação por parte desta instituição, das demandas de alguns setores da sociedade e dos poderes locais e regionais como forma de ampliar suas fileiras e aumentar seu poder e influência, estando muito ligada à vida política do país e à parcela da elite intelectual. No entanto, nos documentos aqui analisados muito é dito sobre o fato de a maçonaria não ser considerada uma associação política, que se envolva com partidos políticos, como pode ser constatado na exposição a seguir:

\begin{abstract}
Nos paizes regidos por instituições livres a Maçonaria não é, e nem deve ser uma associação política. Ahi os sacrosantos princípios por que sempre pugnou têm por defensores a imprensa, a tribuna, toda a organisação política e social. Ella, portanto não precisa, nem deve, envolver-se nas lutas dos partidos, lutas muitas vezes de interesses pessoaes e transitórios, lutas travadas sempre entre homens que, de accôrdo sobre as bases fundamentaes do direito publico, divergem mais ou menos na sua applicacão, conforme o ponto de vista pratico ou theorico em que se collocam. A razão e os interesses de sua causa aconselham-lhe esta abstenção. [...] Mas, si a Maçonaria deve em geral affastar-se dos pleitos dos partidos, não se segue que deve, que possa mesmo ficar indiferente quando, por uma aberração inqualificável, se tente n'esses paizes aniquilar os princípios que, mais do que ninguém, ella proclamou e defendeu, procurando tornal-os os guias seguros e invioláveis das sociedades modernas. (BOLETIM DO GRANDE ORIENTE DO BRAZIL,1891, p. 2).
\end{abstract}

No entanto, não há como negar sua atuação e influência como um autêntico grupo de pressão que aglutinou expressiva parcela da elite imperial e republicana (BARATA, 1999). Sua estrutura organizacional respaldou sua atuação política como grupo assim como as iniciativas de maçons que atuavam na política nacional. Os maçons debateram nas lojas, na imprensa, no Parlamento e nas instituições das quais faziam parte, temas relativos à defesa da liberdade de consciência, da laicização da educação e do progresso do país, do fim do escravismo ${ }^{8}$ e da implantação da República.

Ressalta-se que ainda durante o império brasileiro a atividade maçônica

\footnotetext{
7 Potências maçônicas são os Grande Orientes, Grandes Lojas ou Supremos Conselhos. (FIGUEIREDO, 1996, p. 357).

8 O movimento abolicionista tomou força em meados do século XIX. Em decorrência, principalmente, da pressão inglesa, em 1850 foi decretada a Lei Euzébio de Queiroz, que extinguia o tráfico de escravos. O elaborador dessa lei, o maçom Euzébio de Queiroz, era então ministro da Justiça. Como a escravidão continuava sendo alimentada pelo comércio interno a campanha abolicionista teve nas lojas maçônica um importante espaço para sua articulação. Dentre os muitos maçons que se destacaram nessa causa podese citar Américo Brasiliense, Américo de Campos, Luis Gama, Francisco Glicério, José do Patrocínio, Quintino Bocaiuva, Visconde do Rio Branco, Joaquim Nabuco. Em 1871 foi aprovada a Lei Visconde Rio Branco, que ficou conhecida como a "lei do ventre-livre". A partir dela, filhos de escravos eram considerados livres (CASTELLANI, 1989). No Boletim Maçônico do Grande Oriente do Brasil de março de 1872, há interessante descrição da solenidade comemorativa da Lei de 28 de setembro de 1871 ocorrida na loja desse Grande Oriente.
} 
desenvolvia-se com o apoio e participação da Igreja e do Estado. Dela faziam parte políticos monarquistas e republicanos. As relações entre o clero e a Maçonaria foram relativamente tranquilas até 1872, com a "Questão Religiosa" quando o governo de D. Pedro II decidiu não apoiar a política antimaçônica do Vaticano. A monarquia acabou perdendo o apoio de uma de suas bases de sustentação, a Igreja Católica, o que contribuiu para acelerar a Proclamação da República, em 1889, fato que resultou em grande parte do trabalho de políticos ligados à Maçonaria. Salienta-se que a maçonaria, conforme já abordado anteriormente, se constituiu num terreno fértil para a propagação das ideias iluministas e liberais no século XVIII. Difundiu o uso da razão na busca do progresso intelectual, social e moral e como forma de debelar toda a tirania, seja intelectual, moral ou religiosa. Ideias essas que foram o sustentáculo da modernidade no século XIX e primeiras décadas do século $X X$ e que embasaram mudanças que visavam à construção do que consideravam uma nova sociedade inserida no contexto da Modernidade.

Magalhães (2010, p. 11) destaca que na base da Modernidade está a educação. Como afirma esse autor, a Modernidade

\begin{abstract}
caracterizou-se em linhas gerais, por uma tensão e progressiva harmonização entre os sujeitos e as instituições, por meio da educação. Pragmática e linguagem, a escola e a cultura escolar tornaram-se constitutivas e instituintes da Modernidade, reificando-se como experiência e processo, meio e substância, de aculturação e comunicação, disciplina e organização, intelecção e racionalidade. (MAGALHÃES, 2010, p. 13).
\end{abstract}

Assim, como uma instituição que propugnava o ideal de modernização civilizatória nacional, tinham na educação, na benemerência e na filantropia o sustentáculo de sua atuação. O posicionamento da Maçonaria em relação à instrução (educação) elementar pública, laica e gratuita destinada às classes menos abastadas e a qualificação e profissionalização do professor público é apresentado no primeiro número do Boletim do Grande Oriente do Brazil:

Não exigirá a civilisação moderna, com os mesmos direitos que tinha a antiguidade
para os membros privilegiados da sociedade, uma educação nacional e livre, que
não pode ser dada, senão gratuita? O privilégio nos campos da inteligência parece
ser o maior obstáculo que se oppõe ao desenvolvimento dos destinos da sociedade
e uma causa poderosa da ignorância dos espíritos o da inferioridade moral das
classes menos abastadas. A necessidade de conhecerse a fonte, onde foi bebida a
instrucção e os meios empregados para obtê-lo, a chancelaria de um um
estabelecimento publico ou approvado pela administração, como um privilégio para
a admissão nas universidades ou academias, a negligência dos juizes sobre as
habilitações dos professores públicos, cuja unica direcção deve ser confiado o
ensino, a imposição da acquisição dos conhecimentos acessórios em diversos
ramos de estudo, todas estas distinç̧ões devem desapparecer para que a
instrucção torne-se possível e fácil. A propagação da instrucção pelo povo é uma
idéia que a Inst.'. Mac.'., que abraça a causa da humanidade, deve sempre sustentar
e executar, com o intuito de auxiliar a administração da sociedade na realisação de
medidas, de que depende o seu progresso". (BOLETIM DO GRANDE ORIENTE DO
BRAZIL,1871, p. 11).

Cabe destacar aqui, a iniciativa, liderada pelo maçom Rui Barbosa, de criar, em 1883, a Liga do Ensino, uma associação voltada à defesa do ensino laico. ${ }^{9}$ Conforme

${ }^{9}$ Como afirma Bastos (2007, p. 227), "A Liga tem sua origem na Bélgica (1854), tendo vínculos estreitos com as associações maçônicas, pela defesa da descristianização da escola pela crescente influência Jesuítica. 
aponta Bastos (2007), referenciando-se no jornal carioca Gazeta de Notícias, que em 23 de outubro de 1883 publicou sobre a Liga do Ensino no Brasil, o objetivo da associação era o estudo e a divulgação do ensino público e laico, assim como a promoção de métodos científicos e da moderna pedagogia, tendo em vista melhores condições de trabalho do professorado de escolas públicas e particulares. A atuação desta associação se daria através de discussões em sessões ordinárias, na imprensa, em conferências e com a criação de uma escola modelo de ensino laico.

A Liga de Ensino no Brasil teve, inicialmente, como presidente, Rui Barbosa. A associação contou com 50 sócios fundadores. Pessoas que se destacavam na intelectualidade brasileira, sendo muitos deles, maçons ${ }^{10}$.

O posicionamento da Maçonaria em relação à educação e sua luta pelo ensino público, contra o analfabetismo e em prol da obrigatoriedade do ensino primário, adentra as primeiras décadas do século XX. No jornal maçônico O Templário'11, em 1920, essa temática é apresentada nos quatro primeiros números. Os artigos realizam uma crítica em relação ao descaso com que vinha sendo tratada a instrução pública por parte do governo federal brasileiro. Este, em princípio, responsabilizava-se pelos cursos secundários e superiores, destinados às classes mais abastadas da população, entregando o ensino primário (livre) aos governos estaduais e municipais. Tais governos não se comprometiam na expansão da rede de ensino "à classe pobre, verdadeiramente produtora e laboriosa $e$ que era excluída dos benefícios da instrução e das vantagens por eles produzidas" $(O$ TEMPLÁRIO, 17/01/1920, p. 1).

A educação elementar estendida a todos os brasileiros não era vista como um caminho para mudanças estruturais da sociedade. Seria, isto sim, um caminho que levaria a uma "boa ordem e tranqüilidade pública [...] com homens laboriosos que, com perfeito conhecimento dos seus mystéres, conheçam, também os seus deveres e direitos, e saibam alguma cousa do mundo, suas leis e seus sucessos" (Ibidem).

O ensino elementar obrigatório seria, portanto, uma forma de produzir trabalhadores mais interados nos modernos processos de produção. A educação era considerada como "o factor mais importante e efficaz para estabelecer a fraternidade entre os homens" (O TEMPLÁRIO, 15/02/1928, p. 1). Estimulando as diferenças individuais,

Assim, os objetivos da Liga são contrários às leis existentes, que dão à instrução religiosa o primeiro lugar na escola. Em 1866, Jean Macé funda a Ligue d'enseignement, na França, com objetivo de ensino exclusivamente laico nas escolas públicas e ensino primário gratuito e obrigatório. Estas sociedades fundam escolas modelos, bibliotecas populares, círculos operários, realizam conferências e cursos gratuitos, organizam em cada vila ou comuna um grupo similar de organização e objetivos, mas de ação independente".

10 Os sócios-fundadores foram: Rodolfo Dantas, Menezes Vieira, Dr. Souza Bandeira F., Dr. Sancho de Barros Pimentel, Dr. Ferreira de Araújo, Ferreira Jacobina, Capistrano de Abreu, Dr. Silva Araújo, Dr. Moncorvo, Dr. Franklin Távora, Faro, Dr. Carlos de Carvalho, Borges Carneiro, Dr. Silvio Romero, Alberto Brandão, Lameira de Andrade, Dr. Aquino, Louis Couty, Comendador Ramalho Ortigão, Zeferino Candido, Dr. Ubaldino do Amaral, Fausto Barreto, Silva Maia, Amaro Cavalcanti, Dr. Coelho Rodrigues, Teophilo Leão, Dr. A. Spinola, Dr. Tobias Leite, Joaquim Teixeira de Macedo, Dr. Lima e Castro, A. Pereira leitão, Dr. Aarão Reis, Comendador Fernandes Pinheiro, Machado de Assis, Dr. João Paulo de Carvalho, Bittencourt da Silva, Carlos Jansen, Dr. Americo Barbosa, Dr. Jacy Monteiro, Ullysses Cabral, Dr. Ennes de Souza, Dr. Lyra da Silva, Dr. Theodoreto Souto, Alambary Luz, Dr. Antioco Faure e B. Caldeira (GAZETA DE NOTíCIAS. A Liga do Ensino no Brazil. Rio de Janeiro, 13 de outubro de 1883, apud BASTOS, 2007, p. 229, 230).

11 O Templário foi um jornal maçônico da cidade de Pelotas, RS, que circulou nas décadas de 1920 e 1930. Algumas reflexões aqui realizadas sobre este jornal, resultam de estudos apresentados em Amaral (2005). 
deveria habilitar a população para assumir os diferentes papéis exigidos pela "nova sociedade", ou seja, a sociedade industrial emergente.

Sendo assim, a instrução elementar estendida a todos os brasileiros, resultaria na "ordem e progresso", tão propalada pelo nascente sistema democrático republicano brasileiro.

Também não há como deixar de mencionar aqui aspectos da caridade, benemerência e filantropia maçônica, características que moldam o processo de constituição comportamental do maçom e da própria atuação da maçonaria e que identificam e singularizam sua atuação na sociedade. Como é afirmado no Boletim do Grande Oriente do Brasil,

\begin{abstract}
A caridade, como a primeira virtude social, é a que mais aproxima o homem da divindade, e a que deve distinguir o caracter do maçon em todas as phases da vida humana. [...] A caridade é a base de todas as nossas accões relativamente aos nossos irmãos. É a norma que dirige o nosso zelo e afan pelo bem do gênero humano. Posto que as necessidades dos nossos irmãos nos interessem particularmente, o mérito e a virtude na indigencia, qualquer que seja a pessoa em que se encontre, deve merecer sempre os nossos benefícios e as nossas atenções. (BOLETIM DO GRANDE ORIENTE DO BRAZIL, 1883, p. 67).
\end{abstract}

Analisando atas, correspondências e relatórios ${ }^{12}$, constata-se o empenho dos maçons junto aos trabalhos sociais desenvolvidos pela Maçonaria. Não raros eram aqueles que, bem sucedidos economicamente realizavam vultosas doações em dinheiro ou bens imobiliários, contribuindo no trabalho de auxílio a instituições de caridade e educacionais, assim como com maçons que atravessassem difícil situação financeira. No período aqui estudado, as atitudes filantrópicas eram exaltadas pela imprensa maçônica e profana ${ }^{13}$.

Assim, a partir do século XIX, a maçonaria incorpora discursos de vanguarda que sustentam a modernidade educativa e os maçons passam a se identificar com os princípios do Positivismo. Assumiram, então, a assertiva positivista de que a solução para os problemas nacionais estavam vinculados ao acesso à escolarização. No entanto, há que se ressaltar que, para eles, a solução destes problemas não passava por mudanças estruturais na sociedade. Na realidade, a hierarquia social era apontada pela ordem maçônica como algo natural e que, se assumida por todos, faria parte do processo de evolução sócio-econômica, o que referenda sua identificação com a ideologia positivista. $O$ papel de cada indivíduo no grupo social, quando bem compreendido e aceito, efetivaria, o que consideravam uma nova sociedade, aquela onde imperasse a ordem através de um tutoramento da população por parte daqueles considerados capazes de conduzir os seus destinos. Assim, identificavam-se com os interesses das elites e dos grupos em ascensão social, contemplando também certos anseios das classes menos favorecidas. Nesta lógica, existindo a ordem social, o resultado seria o progresso do país. Situações almejadas, desde meados do século XIX, pelos maçons, liberais e republicanos e que aparecem na bandeira nacional brasileira onde estão estampadas as palavras ordem e progresso. (AMARAL, 2005).

\footnotetext{
12 Muitos desses documentos estão publicados no Boletim do Grande Oriente do Brazil, em periódicos locais de vários municípios brasileiros e em jornais maçônicos.

${ }^{13}$ Cf. Marques (1986, p. 1165) o termo "profano" refere-se a todo indivíduo ou toda a coisa que não pertença à Maçonaria.
} 
Indo ao encontro da concepção maçônica sobre o papel social dos diferentes indivíduos e grupos para a organização e equilíbrio da sociedade, cabe salientar a questão da mulher e o papel que a ela atribuíam. Mas do que isso, o significado dessa compreensão para os movimentos de emancipação da mulher, especialmente no período aqui analisado.

Nesse contexto, em Amaral (2005) considero que a cooptação da mulher para a causa maçônica foi fundamental e alavancou discussões sobre sua inserção social, mormente nas escolas. O que parece à primeira vista uma contradição, uma vez que a instituição maçônica é essencialmente masculina, a preocupação com a educação das mulheres fundamenta-se no fato de ser ela considerada mãe e educadora das futuras gerações, devendo então estar preparada para desempenhar seu papel social. Destacase, no presente trabalho, a presença e participação da portuguesa Ana de Castro Osório no espaço maçônico luso-brasileiro, nas primeiras décadas do século $X X$, através de sua atuação como escritora e defensora da Maçonaria feminina e dos ideais republicanos ${ }^{14}$.

Em janeiro de 1923, O Templário chegou a estampar em sua primeira página uma fotografia de Anna Osório, venerável de uma Loja feminina de Portugal ${ }^{15}$, com as insígnias da Maçonaria. Junto à fotografia, que ocupava a metade da página do jornal, lê-se o seguinte:

\begin{abstract}
Queremos prestar a nossa singela homenagem á brilhante intellectual D. Anna de Castro Osorio que veio pessoalmente espargir no Brasil os lampejos de seu prodigioso talento. Como escriptora, educacionista e propagandista das ideias avançadas, a notavel portugueza conquistou em sua querida Patria uma posição de destaque entre os contemporâneos. (O TEMPLÁRIO, 17/01/1923).
\end{abstract}

Anna Osório, que viveu no Brasil nos anos que antecederam a eclosão da Primeira Guerra Mundial (1911 a 1914), retornou em 1922 para participar das celebrações do centenário de independência do país. Nesta ocasião, realizou conferências em vários estados brasileiros (Rio de Janeiro, São Paulo, Paraná e Rio Grande do Sul). Em sua visita ao Rio Grande do Sul, propagou os ideais republicanos e a importância da Maçonaria Feminina e da união dos maçons frente ao avanço do clericalismo. Suas conferências, proferidas em Lojas de Pelotas e Rio Grande, foram transcritas neste jornal. ${ }^{16} \mathrm{Em}$ seu conteúdo há dominância de um anticlericalismo e de um feminismo, que buscava igualdade de direitos entre as mulheres e os homens na Maçonaria, ressaltando o papel da mulher como mãe e "modeladora" dos filhos:

A mulher já não é hoje o que era hontem e á Maçonaria caberá uma grande responsabilidade se a não chamar a si, porquanto, se ella representa o passado pelas suas tendências naturalmente tradicionalistas, ella representa o futuro pela

\footnotetext{
14 Como afirma Gomes (2011) "Ana de Castro Osório (1872-1935) é uma intelectual razoavelmente reconhecida e estudada em Portugal, sobretudo no contexto das comemorações do Centenário da República, causa que ela ajudou a propagar e com a qual colaborou em projetos importantes, como o do divórcio. [...] Os trabalhos a ela dedicados, concentram-se mais no campo da literatura, no qual teve presença marcante, e, na história, privilegiam sua atuação como líder feminista. [...] [É] autora e editora de manuais escolares e livros infantis que circularam em Portugal e também no Brasil. Apesar desse fato, ela é praticamente uma desconhecida no Brasil, onde viveu entre 1911 e 1914, tendo alguns de seus livros participado da formação da infância de muitos brasileiros, em especial durante os anos 1910 [...]".

${ }^{15}$ Este país era, na época, o único a possuir Lojas exclusivas de mulheres.

${ }^{16}$ As conferências realizadas nas viagens que fez ao Brasil, nesse período, constituiram o livro de sua autoria A Grande Aliança. Este livro foi reeditado em 1997, com o apoio do Instituto Piaget, no ano de seu 125을 aniversário de nascimento e em homenagem, também, ao 175ํaiversário de independência do Brasil.
} 
alma dos filhos de que é modeladora carinhosa. E é da união do passado com o futuro que deve sahir o progresso do presente. [...] (dando-se) à mulher a igualdade de direitos dentro das collumnas dos seus templos [...] só assim a Maçonaria poderá progredir e resistir ás influências contrárias que a atacam, servindo-se exactamente da força feminina desprezada, em igualdade de direitos e deveres. (O TEMPLÁRIO, 17/01/1923, p. 4.).

A Maçonaria, contrapondo-se ao papel de desigualdade social da mulher perante o homem, reforçado, segundo os maçons, pelo catolicismo, utilizou-se do apoio à causa feminina na disputa pela primazia de suas ideias, desenvolvendo um discurso e até mesmo uma prática voltada aos interesses feministas. Nesta afronta ao clericalismo, a legalização do divórcio passa a ser amplamente debatida e defendida pelos maçons, assim como a participação feminina junto a esta instituição. Ao mesmo tempo, a presença da mulher na Maçonaria fazia parte de uma ideia de reconstrução social que servisse para auxiliar na solução dos problemas vividos no início do século XX. A colaboração da mulher foi vista como essencial na cruzada moralizadora em que se empenhou esta Instituição e que tinha como alvo principal o clericalismo vigente. Como a instituição maçônica vinculava as mudanças sociais à questão educacional e sendo a mulher o sustentáculo da Igreja Católica, a Maçonaria passou a propugnar a ideia de que era necessário tirar a mulher do domínio do catolicismo romano para que houvesse realmente uma reforma educacional.

\section{Considerações finais}

No período estudado, a maçonaria brasileira, como espaço de sociabilidade, tem nos ideais de liberdade, igualdade e fraternidade, a sustentação de seus discursos que buscam respaldar suas práticas sociais e políticas. O papel dos maçons foi essencialmente levar essas discussões para o campo político e social em que atuavam.

E é, nesse sentido, que o presente estudo busca ressaltar a importância de que se leve em conta a filiação maçônica de determinados indivíduos que se destacaram no espaço político-educacional brasileiro. Suas práticas, propostas e decisões, provavelmente foram discutidas e gestadas no espaço das lojas maçônicas, junto ao grupo do qual faziam parte. E essa era uma das importantes finalidades desse grupo: ser um espaço de sociabilidade, de discussão de ideias ancoradas nos pressupostos da modernidade.

No Brasil, o processo de laicização do ensino decorrente da Proclamação da República, resultou no acirramento das disputas entre a Maçonaria e a Igreja Católica pela primazia no campo educacional. Para os maçons, o clero através de sua ação pastoral e, especialmente da Companhia de Jesus, atuando junto à educação das elites, sedimentava conceitos e condutas que perpetuavam uma organização social arcaica que levava o país ao atraso. Os maçons, embora muito próximos das premissas do Positivismo, distanciavam-se delas ao defenderem a existência do ensino elementar obrigatório, público, laico e gratuito como forma de garantir o efetivo desempenho da função que delegava à educação formal: manutenção da coesão social e a diminuição da influência das escolas particulares confessionais. As ideias positivistas de separação entre a Igreja e o Estado, de liberdade espiritual, de valorização da tradição, da família, do dever, da hierarquia social, serviram de sustentáculo aos propósitos defendidos pelos maçons, sobretudo no campo educacional. A ação dos maçons na modernização educacional inclui designadamente práticas políticas como intelectuais, gestores, legisladores, escritores, jornalistas, professores, bem como a fundação de lojas maçônicas, a criação de periódicos, a 
publicação de livros, a fundação de bibliotecas, de escolas, de faculdades e de obras de benemerência voltadas aos mais necessitados. Portanto, é preciso não perder de vista sua atuação e o que isto representou na oposição ao discurso conservador do catolicismo romano: indubitavelmente uma importante e destacada referência no processo de modernização educativa na emergente república brasileira.

\section{Referências}

AGULHON, Maurice. Pénitents et francs-maçons de l'ancienne Provence. Paris: Seuil, 1968.

AMARAL, Giana Lange do. O Gymnasio Pelotense e a Maçonaria: uma face da história da educação em Pelotas. 2 ed. Pelotas: Seiva Publicações, 2005.

AZEVEDO, Célia M. Marinho de. Maçonaria: história e historiografia. Revista USP, São Paulo, v. 32, p. 178-189, dez/fev. 1997.

BASTOS, Maria Helena Camara. Apresentação: a Liga do Ensino no Brasil e a Revista Liga do Ensino (1883-1884). Revista História da Educação, ASPHE, Pelotas, Fae/UFPel, v. 11, n. 21, p. 225-246, jan./abr. 2007.

BENIMELI, J.; CAPRILE, G.; ALBERTON, V. Maçonaria e Igreja Católica: ontem hoje e amanhã. 2 ed. São Paulo: Paulinas, 1983.

BOLETIM DO GRANDE ORIENTE DO BRAZIL. Jornal Official da Maçonaria Brasileira. N. 1, Dezembro, $1^{\circ}$ anno, 1871 Jornal Official da Maçonaria Brasileira. N. 7 a 9. $12^{\circ}$ anno, 1883.

CASTELLANI, José. A Maçonaria e o movimento republicano brasileiro. São Paulo: Editora Traço, 1989.

CANAL, Jordi. Maurice Agulhon e a categoria sociabilidade. Revista Ler História [on line], n. 68, 2015. Disponível em: <http://lerhistoria.revues.org/1780>. Acesso em: 26 jan.2017.

CHARTIER, Roger. História Cultural: entre práticas e representações. Lisboa: Difel, 1990.

CHAUNU, Pierre; DUBY, Georges; LE GOFF, Jaques; NORA, Pierre; e outros. Ensaios de Ego-história. Lisboa, Portugal: Edições 70, 1987.

GOMES, Ângela de Castro. A Grande Aliança de Ana de Castro Osório: um projeto político-pedagógico fracassado. Estudos do Século XX, n. 11, Portugal: Imprensa da Universidade de Coimbra, 2011.

GUIMARÃES, Farias. O que é maçonaria? Pelotas: Loja Simbólica Fraternidade, 1946.

FIGUEIREDO Joaquim Gervásio de. Dicionário de maçonaria. Seus mistérios, ritos, filosofia, história. São Paulo: Editora Pensamento, 1996.

HABERMAS, Jürgen. La Constelación Posnacional: ensayos políticos. Barcelona/Buenos Aires/México: Paidós, 2000.

LUCA, Tânia Regina de. Fontes impressas: história dos, nos e por meio dos periódicos. In: PINSKI, Carla B. (Org.). Fontes históricas. São Paulo: Contexto, 2005, p. 111-153

MAGALHÃES, Justino. Da cadeira ao banco: escola e modernização (séculos XVIII-XX). Lisboa: Instituto de Educação, Universidade de Lisboa, 2010.

MARQUES, A. H. de Oliveira. Dicionário da Maçonaria Portuguesa. Lisboa: Editorial Delta, 1986.

MOREL, Marco. Sociabilidades entre Luzes e sombras: apontamentos para o estudo 
histórico das maçonarias da primeira metade do século XIX. Estudos Históricos, Rio de Janeiro, n. 28, 2001, p. 3-22, 2001.

MOREL, Marco; SOUZA, Françoise Jean de Oliveira. O poder da maçonaria: a história de uma sociedade secreta no Brasil. Rio de Janeiro: Nova Fronteira, 2008.

O TEMPLÁRIO. Órgão das Lojas Unidas "Honra e humanidade, Rio Branco e Lealdade". Pelotas, RS, 1920-1935.

GIANA LANGE DO AMARAL é professora do Programa de Pós-Graduação em Educação da Universidade Federal de Pelotas, pesquisadora CNPQ/PQ2, Doutora em Educação pela Universidade Federal do Rio Grande do Sul, com estágio Pós-doutoral na Universidade de Lisboa e na PUC/RS.

Endereço: Rua Três de Maio, 973 - 96010-620 - Pelotas/RS, Brasil.

E-mail: gianalangedoamaral@gmail.com

Recebido em 03 de março de 2017.

Aceito em 24 de maio de 2017. 